\title{
Formulasi dan Evaluasi Sediaan Roll On Aromaterapi Blended Peppermint, Lavender dan Lemon sebagai Antiemetika
}

\author{
Annisa Fatmawati $i^{1}$, Isti Chana Zuliyati ${ }^{2}$, Sundari Mulyaningsih ${ }^{2}$ \\ ${ }^{1}$ Program Studi Sarjana Farmasi, Fakultas IImu-IImu Kesehatan, Universitas Alma Ata \\ ${ }^{2}$ Program Studi Sarjana Kebidanan, Fakultas IImu-IImu Kesehatan, Universitas Alma Ata \\ Email : annisafatma20@almaata.ac.id, isti.chana@almaata.ac.id, sundari.mulya@almaata.ac.id

\section{Korespondensi:} \\ Annisa Fatmawati \\ Program Studi Sarjana Farmasi, Fakultas Ilmu-Ilmu Kesehatan, Universitas Alma Ata \\ Email Korespondensi: annisafatma20@almaata.ac.id
}

\begin{abstract}
Abstrak
Penggunaan sediaan aromaterapi pada kondisi mual dan muntah bermanfaat untuk meningkatkan keadaan fisik dan psikologi seseorang menjadi lebih baik. Beberapa minyak esensial memiliki efek farmakologi seperti penenang, ketika dihirup melalui rongga hidung dapat merangsang sistem limbik di otak. Peppermint dan lemon termasuk dalam golongan top notes dan lavender termasuk dalam golongan middle notes minyak atsiri, dan golongan base notes seperti minyak nilam dan virgin coconut oil. Penelitian ini bertujuan untuk membuat formulasi sediaan aromaterapi kombinasi (blended) dan evaluasi sediaan, yang dapat digunakan untuk mengurangi kondisi mual dan muntah sebagai terapi non farmakologi. Pembuatan aromaterapi roll on dilakukan dengan menakar bahan sesuai formula kemudian dicampur dalam beaker glass dan di vortex selama 15 menit, selanjutnya dilakukan evaluasi sifat fisik. Hasil uji stabilitas fisik menunjukkan semua formula roll on minyak aromaterapi blended memenuhi syarat uji organoleptik, uji homogenitas, pengukuran derajat keasaman $(\mathrm{pH})$ dan uji daya sebar. Formula F1B sediaan roll on (Kombinasi lavender $40 \%$, lemon $50 \%$, dan VCO $10 \%$ ) merupakan formula terbaik berdasarkan penampilan fisik organoleptik, derajat keasaman dan uji daya sebar.
\end{abstract}

Kata Kunci: antiemetika; lavender; lemon; peppermint; roll on

\section{FORMULATION AND EVALUATION OF ROLL ON AROMATHERAPY OF BLENDED PEPPERMINT, LAVENDER AND LEMON AS ANTIEMETICS}

\begin{abstract}
The use of aromatherapy preparations in conditions of nausea and vomiting is useful for improving a person's physical and psychological state for the better. Some essential oils have pharmacological effects such as sedation, when inhaled through the nasal cavity can stimulate the limbic system in the brain. Peppermint and lemon are included in the top notes, and lavender is included in the middle notes, essential oils, and base notes, such as patchouli oil and virgin coconut oil. This study aims to formulate a combination (blended) aromatherapy preparation and evaluate the preparation, which can be used to reduce
\end{abstract}


nausea and vomiting as a non-pharmacological therapy. The manufacture of aromatherapy roll on is done by measuring the ingredients according to the formula then mixed in a glass beaker and vortexed for 15 minutes, then the physical properties are evaluated. The results of the physical stability test showed that all roll on blended aromatherapy oil formulas met the requirements of organoleptic test, homogeneity test, measurement of acidity $(\mathrm{pH})$ and spreadability test. Formula F1B roll-on preparation (a combination of $40 \%$ lavender, $50 \%$ lemon, and 10\% VCO) is the best formula based on organoleptic physical appearance, acidity degree and dispersibility test.

Keywords: peppermint, lavender, lemon, roll on, antiemetic

Received: 11 September 2021

Accepted: 21 Desember 2021

\section{PENDAHULUAN}

Kondisi mual dan muntah, pada umumnya dikaitkan dengan implikasi positif, gejala-gejala ini dapat secara signifikan mempengaruhi kehidupan pribadi dan profesional seseorang. Penelitian telah menunjukkan bahwa mual dan muntah pada kehamilan memiliki dampak yang signifikan pada kehidupan keluarga, kemampuan untuk mengerjakan aktivitas sehari-hari, bersosialisasi, dan kondisi psikologi. Selain itu, gejalagejala mual dan muntah juga dapat mempengaruhi kualitas hidup dalam hal aspek fisiologis dan mental ${ }^{1}$.

Vitamin B6 menjadi salah satu antiemetika lini pertama untuk ibu hamil yang mengalami mual dan muntah. Namun, sebagian besar ibu hamil memerlukan antiemetika tambahan, seperti dimenhydrinate dan promethazine. Obat-obatan ini dapat menimbulkan efek samping seperti sedasi, kekeringan mulut, kelemahan motorik dan gangguan penglihatan. Kekhawatiran tentang efek teratogenik dari obat-obatan antiemetika pada awal kehamilan, dapat diberikan alternatif terapi non farmakologi yang dapat digunakan untuk meminimalkan mual dan muntah pada kehamilan².

Penggunaan sediaan aromaterapi merupakan tindakan teraupetik dengan menggunakan minyak esensial yang bermanfaat untuk meningkatkan keadaan fisik dan psikologi seseorang menjadi lebih baik. Beberapa minyak esensial memiliki efek farmakologi yang unik seperti penenang, perangsang adrenalin, anti bakteri, antivirus, diuretik dan vasodilator. Molekul kimia atsiri dalam minyak esensial tersebut ketika dihirup melalui rongga hidung dapat merangsang sistem limbik di otak ${ }^{3}$. 
Peppermint termasuk dalam golongan top notes dan lavender termasuk dalam golongan middle notes minyak atsiri, dan golongan base notes seperti minyak nilam dan virgin coconut oil. Formulasi aromaterapi perlu diperhatikan pembuatan komposisi formula aromaterapi yang tepat/ blended essential oil preparation ${ }^{4}$. Minyak kelapa adalah minyak nabati yang diperoleh dari kelapa sawit, dapat digunakan sebagai base notes ${ }^{5}$. Berbagai literatur dan laporan medis VCO merupakan minyak yang banyak digunakan dalam bidang farmasi dan cosmeceuticals, sebagai minyak dengan sifat terapeutik. VCO digunakan sebagai pelembab tubuh, pembawa aromaterapi/ base notes, kondisioner rambut ${ }^{6,7}$. Peppermint mengandung senyawa 1,8-Sineol dan menthol (Gambar 1). Peppermint merupakan monoterpen yang diekstraksi dari minyak mint, Mentha spp ${ }^{8}$. Kandungan atsiri utama lavender antara lain linalool, linalylacetat, 1,8-cineole B-ocimene, terpinen-4-ol, dan kamper. Linalool merupakan komponen lavender yang memiliki efek sebagai zat sedatif dan biasa digunakan sebagai aromaterapi yang mempengaruhi sistem neuroendokrin tubuh yang berpengaruh terhadap pelepasan hormon dan neurotransmitter ${ }^{3}$. Minyak atsiri lemon adalah minyak essensial yang dihasilkan dari ekstrak kulit jeruk (Citrus lemon) yang sering digunakan dalam aromaterapi. Aromaterapi lemon adalah jenis aromaterapi yang aman untuk kehamilan dan melahirkan ${ }^{9}$. Minyak nilam dalam penelitian Siahaan et al., (2014), juga digunakan sebagai based notes, dimana campurannya dengan sereh dan kenanga, dapat menurunkan tingkat stres pada wanita sehat ${ }^{10}$. Penelitian ini bertujuan untuk membuat formulasi sediaan aromaterapi kombinasi (blended) dan evaluasi sediaan, yang dapat digunakan untuk mengurangi kondisi mual dan muntah sebagai terapi non farmakologi.

\section{METODE PENELITIAN}

\section{Alat dan Bahan}

Penelitian ini menggunakan alat gelas (pyrex), botol kaca roll on, alat uji homogenitas, daya sebar dan $\mathrm{pH}$ Universal. Bahan yang digunakan dalam penelitian ini adalah minyak bahan alam Peppermint, Lavender, Lemon, Nilam dan VCO (virgin coconut oil) dari Toko Tekun Jaya di Yogyakarta.

\section{Rancangan Penelitian}

Penelitian ini dilaksanakan di Laboratorium Teknologi Farmasi, Fakultas IImu-IImu Kesehatan, Universitas Alma Ata. Sediaan aromaterapi sebagai antiemetika dibuat 
dengan mencampur minyak atsiri (blended essential oil preparation) sesuai dengan kombinasi aturan pencampuran minyak atsiri. Komposisi campuran minyak atsiri terdiri dari top notes $20-40 \%$, middle notes $50-70 \%$, dan $10 \%$ base notes ${ }^{4}$. Formula kombinasi Minyak Peppermint, Lavender dan Lemon untuk aromaterapi terdapat pada Tabel 1.

Tabel I. Formula Aromaterapi Blended Minyak Peppermint, Lavender dan Lemon

\begin{tabular}{lcccccc}
\hline \multirow{2}{*}{ Minyak (mI) } & \multicolumn{7}{c}{ Blended Aromaterapi } \\
\cline { 2 - 7 } & F1A & F2A & F3A & F1B & F2B & F3B \\
\hline Peppermint & 4 & 3 & 2 & - & - & - \\
Lavender & 5 & 6 & 7 & 4 & 3 & 2 \\
Lemon & - & - & - & 5 & 6 & 7 \\
VCO & - & - & - & 1 & 1 & 1 \\
Nilam & 1 & 1 & 1 & - & - & - \\
\hline
\end{tabular}

Keterangan: VCO (Virgin Coconut Oil)

$\mathrm{F} 1 \mathrm{~A}=$ Kombinasi formula peppermint $40 \%$, lavender $50 \%$, dan nilam $10 \%$

F2A $=$ Kombinasi formula peppermint $30 \%$, lavender $60 \%$, dan nilam $10 \%$

$\mathrm{F} 3 \mathrm{~A}=$ Kombinasi formula peppermint $20 \%$, lavender $70 \%$, dan nilam $10 \%$

$\mathrm{F} 1 \mathrm{~B}=$ Kombinasi formula lavender $40 \%$, lemon $50 \%$, dan VCO $10 \%$

$\mathrm{F} 2 \mathrm{~B}=$ Kombinasi formula lavender $30 \%$, lemon $60 \%$, dan VCO $10 \%$

$\mathrm{F} 3 \mathrm{~B}=$ Kombinasi formula lavender $20 \%$, lemon $70 \%$, dan VCO $10 \%$

Formula aromaterampi blended pada Tabel 1, dicampur menggunakan alat beaker glass dan diaduk dengan magnetic stirrer. Masing-masing formula dibuat menjadi $100 \mathrm{ml}$ dan dimasukkan dalam kemasan roll on ukuran $10 \mathrm{ml}$. Evaluasi stabilitas fisik minyak aromaterapi blended melalui pengamatan organoleptik, uji homogenitas, pengukuran derajat keasaman $(\mathrm{pH})$ dan uji daya sebar ${ }^{11,12}$.

\section{HASIL DAN PEMBAHASAN}

\section{Pengamatan Organoleptik}

Uji stabilitas fisik sedian aromaterapi blended dilakukan dengan pengamatan organoleptik dengan hasil terdapat pada Tabel 2. Hasil uji organoleptis pada semua bentuk perlakuan memiliki hasil yang sama pada warna, bentuk dan bau yaitu untuk sediaan dengan base note nilam memiliki warna oranye, bentuk cair dan bau khas sangat kuat. Senyawa patchoulol yang terdapat dalam minyak nilam menghasilkan efek stimulan dan sedative. Minyak atsiri untuk aromaterapi juga memerlukan campuran tiga jenis minyak yang memiliki tingkat penguapan yang berbeda, dimana nilam termasuk dalam "base note", sehingga aromanya dapat bertahan lebih lama ${ }^{10}$. 


\section{Uji Homogenitas}

Hasil uji homogenitas sediaan aromaterapi blended dengan kombinasi base note minyak nilam dan VCO memiliki homogenitas yang baik. Bahan dalam formulasi F1A, F2A, F3A, F1B, F2B, F3B dapat tercampur dengan baik, seperti hasil yang terdapat pada Tabel 2. Minyak yang digunakan dalam formulasi sediaan aromaterapi ini dapat bercampur dan tidak mengalami inkompatibilitas, dengan prinsip like dissolve like, suatu senyawa akan terlarut pada pelarut yang mempunyai sifat yang sama, yakni pelarut nonpolar akan melarutkan senyawa nonpolar ${ }^{10,11}$.

Tabel II. Pengamatan Organoleptik Aromaterapi Peppermint, Lavender dan Lemon

\begin{tabular}{ccccc}
\hline \multirow{2}{*}{ Formula } & \multicolumn{3}{c}{ Uji Organoleptis } & Homogenitas \\
\cline { 3 - 4 } & Warna & Bentuk & Bau & \\
\hline F1A, F2A, F3A & Kuning kecoklatan & Cair & Khas, sangat kuat & homogen \\
F1B, F2B, F3B & Putih kekuningan & Cair & Khas, kuat & homogen \\
\hline
\end{tabular}

Keterangan: VCO (Virgin Coconut Oil)

$\mathrm{F} 1 \mathrm{~A}=$ Kombinasi formula peppermint $40 \%$, lavender $50 \%$, dan nilam $10 \%$

$\mathrm{F} 2 \mathrm{~A}=$ Kombinasi formula peppermint $30 \%$, lavender $60 \%$, dan nilam $10 \%$

$F 3 A=$ Kombinasi formula peppermint $20 \%$, lavender $70 \%$, dan nilam $10 \%$

$\mathrm{F} 1 \mathrm{~B}=$ Kombinasi formula lavender $40 \%$, lemon $50 \%$, dan VCO $10 \%$

$\mathrm{F} 2 \mathrm{~B}=$ Kombinasi formula lavender $30 \%$, lemon $60 \%$, dan VCO $10 \%$

$\mathrm{F} 3 \mathrm{~B}=$ Kombinasi formula lavender $20 \%$, lemon $70 \%$, dan VCO $10 \%$

Tabel III. Hasil pengukuran derajat keasaman (pH) Sediaan Roll On Aromaterapi

\begin{tabular}{ccccccc}
\hline \multirow{2}{*}{ Replikasi } & F1A & F2A & F3A & F1B & F2B & F3B \\
\cline { 2 - 7 } & 5,00 & 5,00 & 5,00 & 5,00 & 5,00 & 5,00 \\
2 & 5,00 & 5,00 & 5,00 & 5,00 & 5,00 & 5,00 \\
3 & 5,00 & 5,00 & 5,00 & 5,00 & 5,00 & 5,00 \\
\hline \multirow{2}{*}{ Rata-rata \pm SD } & $5,00 \pm$ & $5,00 \pm$ & $5,00 \pm$ & $5,00 \pm$ & $5,00 \pm$ & $5,00 \pm$ \\
& 0,00 & 0,00 & 0,00 & 0,00 & 0,00 & 0,00 \\
\hline
\end{tabular}

Keterangan: VCO (Virgin Coconut Oil)

$\mathrm{F} 1 \mathrm{~A}=$ Kombinasi formula peppermint $40 \%$, lavender $50 \%$, dan nilam $10 \%$

$\mathrm{F} 2 \mathrm{~A}=$ Kombinasi formula peppermint $30 \%$, lavender $60 \%$, dan nilam $10 \%$

$\mathrm{F} 3 \mathrm{~A}=$ Kombinasi formula peppermint $20 \%$, lavender $70 \%$, dan nilam $10 \%$

$\mathrm{F} 1 \mathrm{~B}=$ Kombinasi formula lavender $40 \%$, lemon $50 \%$, dan VCO $10 \%$

$\mathrm{F} 2 \mathrm{~B}=$ Kombinasi formula lavender $30 \%$, lemon $60 \%$, dan VCO $10 \%$

$\mathrm{F} 3 \mathrm{~B}=$ Kombinasi formula lavender $20 \%$, lemon $70 \%$, dan VCO $10 \%$

INPHARNMED Journal, Vol.5, No.2, Tahun 2021, 8-16

Available from: http://ejournal.almaata.ac.id/index.php/INPHARNMED 


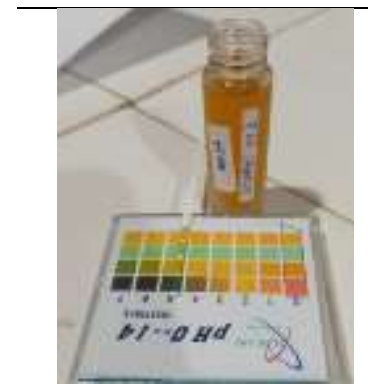

F1A

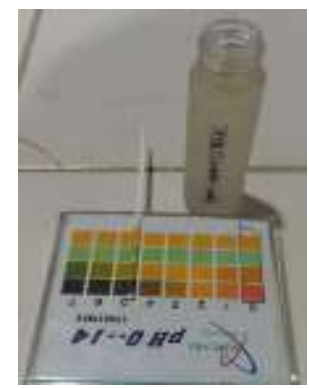

F1B

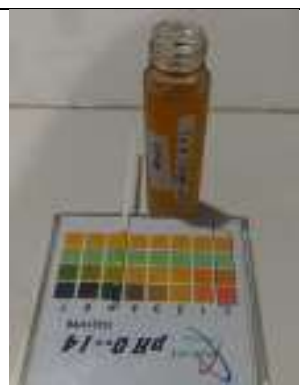

F2A

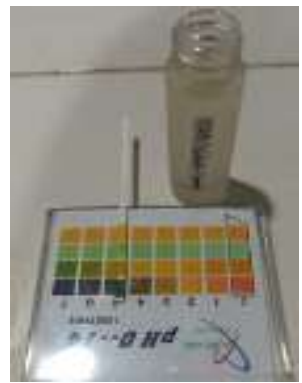

F2B

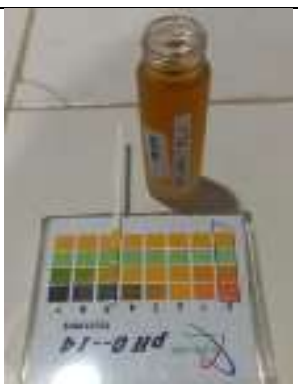

F3A

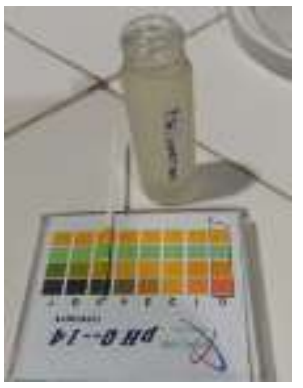

F3B

Gambar 1. Hasil Uji Derajat Keasaman (pH) Sediaan Aromaterapi

\section{Pengukuran pH (Derajat Keasaman)}

Berdasarkan hasil pengukuran derajat keasaman menggunakan kertas $\mathrm{pH}$ Universal menunjukkan bahwa $\mathrm{pH}=5$ pada semua formula sediaan minyak aromaterapi. Hasil uji pada Tabel 3, menunjukkan bahwa $\mathrm{pH}$ pada semua formulasi dalam kategori aman bagi kulit, dan memenuhi syarat untuk pH sediaan topikal yaitu 4,5-6,5. Kesesuaian nilai pH pada sediaan topikal akan mempengaruhi keasaman atau kebasaan sehingga kulit tidak mengalami iritasi ${ }^{13}$. Hasil pengukuran derajat keasaman $\mathrm{pH}$ pada formulasi aromaterapi roll on terdapat pada Gambar 1.

\section{Uji Daya Sebar}

Uji daya sebar dilakukan dengan menuangkan 0,50 gram sediaan aromaterapi ke tengah-tengah kaca, selanjutnya ditutup dengan kaca lain yang telah ditimbang dan dibiarkan selama satu menit selanjutnya diukur diameter dan diberi penambahan beban tiap satu menit 25 gram hingga 250 gram selama 5 menit, kemudian diukur diameter sebar menggunakan penggaris ${ }^{13}$. Rata - rata hasil uji daya sebar terdapat pada Tabel 4.

Berdasarkan Tabel 4, rata-rata uji daya sebar sedian aromaterapi berada pada rentang 6.3 - 7.6. Uji daya sebar paling tinggi pada formulasi F1A sedangkan paling rendah pada F3B. Persyaratan daya sebar yang baik yaitu sekitar $5-7 \mathrm{~cm}$, sehingga semua formula sediaan minyak aromaterapi memenuhi syarat uji daya sebar ${ }^{13}$. 
Tabel IV. Hasil Uji Daya Sebar Sediaan Aromaterapi

\begin{tabular}{ccccccc}
\hline \multirow{2}{*}{ Replikasi } & \multicolumn{7}{c}{ Uji Daya Sebar (cm) } \\
\cline { 2 - 7 } & F1A & F2A & F3A & F1B & F2B & F3B \\
\hline 1 & 7,8 & 7,6 & 7,7 & 7,6 & 6,4 & 6,0 \\
2 & 7,6 & 7,5 & 7,4 & 7,5 & 6,3 & 6,2 \\
3 & 7,4 & 7,9 & 7,3 & 7,6 & 6,5 & 5,9 \\
\hline \multirow{2}{*}{ Rata-rata + SD } & $7,60 \pm$ & $7,67 \pm$ & $7,47 \pm$ & $7,57 \pm$ & $6,40 \pm$ & $6,03 \pm$ \\
& 0,20 & 0,21 & 0,21 & 0,06 & 0,10 & 0,15
\end{tabular}

Keterangan: VCO (Virgin Coconut Oil)

$\mathrm{F} 1 \mathrm{~A}=$ Kombinasi formula peppermint $40 \%$, lavender $50 \%$, dan nilam $10 \%$

$\mathrm{F} 2 \mathrm{~A}=$ Kombinasi formula peppermint $30 \%$, lavender $60 \%$, dan nilam $10 \%$

$\mathrm{F} 3 \mathrm{~A}=$ Kombinasi formula peppermint $20 \%$, lavender $70 \%$, dan nilam $10 \%$

$\mathrm{F} 1 \mathrm{~B}=$ Kombinasi formula lavender $40 \%$, lemon $50 \%$, dan VCO $10 \%$

F2B $=$ Kombinasi formula lavender $30 \%$, lemon $60 \%$, dan VCO $10 \%$

$\mathrm{F} 3 \mathrm{~B}=$ Kombinasi formula lavender $20 \%$, lemon $70 \%$, dan VCO $10 \%$

Penelitian Andriani dan Yuni (2017), menunjukkan bahwa ada pengaruh aromaterapi peppermint terhadap penurunan kondisi mual dan muntah pada ibu hamil trimester satu ${ }^{14}$. Penelitian Santi (2013), menginformasikan bahwa penggunaan aromaterapi blended peppermint dan ginger oil oleh ibu hamil trimester satu adalah salah satu cara alternatif untuk menurunkan frekuensi rasa mual karena terbukti penggunaannya mudah, sederhana, efektif, dan tanpa efek samping serta tidak merugikan kondisi ibu dan calon bayi. Jenis minyak essensial yang biasa digunakan untuk blended aromaterapi adalah peppermint, spearmint, lemon, jahe dan lavender ${ }^{15,16}$.

Lavender mengandung senyawa monoterpen, yang bersifat lipofilik terhadap membran sel, dan menyebabkan perubahan aktivitas saluran ion, pembawa dan reseptor saraf. Khasiat tersebut dapat menjelaskan efek menenangkan dan mengurangi mual dan muntah dari minyak Lavender ${ }^{7,16,17}$. Pemberian inhalasi sediaan aromaterapi lemon dapat menurunkan frekuensi emesis gravidarum lebih baik dibanding vitamin $\mathrm{B}^{9}$. Pencampuran lavender dan lemon pada minyak aromaterapi untuk pemijatan, dapat meningkatkan sistem imunitas tubuh ${ }^{18}$. Menghirup minyak esensial campuran akan meminimalkan kejadian mual dan muntah, meningkatkan energi dan meminimalkan kelelahan pada ibu hamil ${ }^{16}$. Menghirup dua campuran minyak lavender, lemon dan peppermint dapat meminimalkan kejadian mual, meningkatkan energi tubuh dan mengurangi rasa kelelahan ${ }^{2,19}$ 


\section{KESIMPULAN DAN SARAN}

Formula sediaan aromaterapi blended F1B (Kombinasi lavender 40\%, lemon 50\%, dan VCO 10\%) merupakan formula terbaik berdasarkan penampilan fisik organoleptik, derajat keasaman dan uji daya sebar. Sediaan aromaterapi kombinasi lemon dan lavender dapat digunakan untuk alternatif terapi non farmakologi pada kondisi mual dan muntah.

Saran untuk pengembangan formula aromaterapi ini perlu ditambahkan antioksidan, uji angka asam dan dilakukan uji mikrobiologi. Kombinasi minyak peppermint dan lavender dapat ditambahkan VCO atau minyak bunga matahari sebagai base note agar dapat memperbaiki penampilan warna secara organoleptik.

\section{UCAPAN TERIMA KASIH}

Ucapan terimakasih kami sampaikan pada Kemenristek DIKTI, LL Dikti Wilayah V, dan Universitas Alma Ata yang telah memberikan fasilitas untuk pelaksanaan penelitian formulasi sediaan aromaterapi sebagai antiemetika.

\section{KONFLIK KEPENTINGAN}

Seluruh penulis menyatakan tidak terdapat potensi konflik kepentingan dengan penelitian dan atau publikasi artikel ini.

\section{DAFTAR PUSTAKA}

1. Joulaeerad N, Ozgoli G, Hajimehdipoor H, Ghasemi E, Salehimoghaddam F. Effect of aromatherapy with peppermint oil on the severity of nausea and vomiting in pregnancy: A single-blind, randomized, placebo-controlled trial. J Reprod Infertil. 2018;19(1):32-8.

2. Mahmoud R, Ghani A, Tawfik A, Ibrahim A. The Effect of Aromatherapy Inhalation on Nausea and Vomiting in Early Pregnancy: A Pilot Randomized Controlled Trial. 2013;3(6):10-22.

3. Rosalinna R. Aromaterapi Lavender Terhadap Pengurangan Mual Muntah Pada Ibu Hamil. Jambura Heal Sport J. 2019;1(2):48-55.

4. Hongratanaworakit T, Soontornmanokul S, Wongareesanti P. Development of aroma massage oil for relieving muscle pain and satisfaction evaluation in humans. J Appl Pharm Sci. 2018;8(4):126-30.

5. Shijna Kappally AS and AS. a Review of Potential Applications. HygeiaJDMed. 2015;7(2):34-41.

6. Jayasekara C, Gunathilake K. Processing technologies for virgin coconut oil and coconut based Confectionaries and beverages. Proc Int ... [Internet]. 2007;(August). Tersedia pada: https://www.researchgate.net/profile/KD_Prasanna_Gunathilake/ 
publication/256765889_Processing_technologies_for_virgin_coconut_oil_and_coco nut_based_Confectionaries_and_beverages/links/55ce1f9a08ae118c85be09ce.pdf

7. Songkro S, Sirikatitham A, Sungkarak S, Buaking K, Wungsintaweekul J, Maneenuan D, et al. Characterization of aromatherapy massage oils prepared from virgin coconut oil and some essential oils. JAOCS, J Am Oil Chem Soc. 2010;87(1):93-107.

8. Prasetya Toepak E, Retnowati R. Isolasi Dan Karakterisasi Terhadap Minyak Mint Dari Daun Mentha Arvensis Segar Hasil Distilasi Uap-Air. Kim student J [Internet]. 2013;2(2):574-9. Tersedia pada: http://download.portalgaruda.org/article.php? article $=191475 \&$ val=6488\&title=Isolasi dan Karakterisasi Terhadap Minyak Mint dari Daun Mentha Arvensis Segar Hasil Distilasi Uap-Air

9. Sari SP, Sabarudin U, Hartiningsih SS, Wijayanegara H. Perbandingan Pengaruh Inhalasi Aromaterapi Lemon dan Vitamin B6 Terhadap Penurunan Frekuensi Emesis Gravidarum pada Ibu Primigravida Trimester I. Jsk. 2019;5(71):8-12.

10. Siahaan R, Rahardjo TB, Ranti A. Effectiveness of Indonesian Essential Oil Mixture of Lemongrass, Cananga, and Patchouli in Relaxation through Inhalation: A Clinical Test on Healthy Woman with High Potential for Stress. Makara J Heal Res. 2014;18(3):14351.

11. St. Rahmah Syam, Arisanty, Hendra Stevani, Ratna Sari Dewi HS. Formulasi dan stabilitas sediaan Roll On Aromaterapi Jahe (Zingiber officinale) Dengan Variasi Konsentrasi Butil Hidroksi Toluen. 2021;XVII(1).

12. Hajrin W, Subaidah WA, Juliantoni Y, Wirasisya DG. Application of Simplex Lattice Design Method on The Optimisation of Deodorant Roll-on Formula of Ashitaba (Angelica keiskei). J Biol Trop. 2021;21(2):501.

13. Sawiji RT, Oriana E, La J, Sukarmini NK. STABILITAS SEDIAAN GEL AROMATERAPI KULIT BUAH JERUK LIMAU ( Citrus amblycarpa ( Hassk .) Ochse ). Lomb J Sciene. 2020;2(2):15-21.

14. Andriani AW. Pengaruh Aromaterapi Peppermint Terhadap Kejadian Mual Dan Muntah Pada Ibu Hamil Trimester I Di Puskesmas Mlati II Sleman Yogyakarta. Universitas "Aisyiyah Yogyakarta. Jurnal. 2017;

15. Santi DS. Pengaruh Aromaterapi Blended Peppermint dan Ginger Oil terhadap Rasa Mual pada Ibu Hamil Trimester Satu di Puskesmas Rengel Kabupaten Tuban. J Sains Med [Internet]. 2013;5(2):52-5. Tersedia pada: https://www.kopertis7.go.id/ uploadjurnal/Dwi_Rukma_Santi_stikes_nu_tuban.pdf

16. Olapour A, Behaeen K, Akhondzadeh R, Soltani F, Razavi FAS, Bekhradi R. The effect of inhalation of aromatherapy blend containing lavender essential oil on cesarean postoperative pain. Anesthesiol Pain Med. 2013;3(1):203-7.

17. Rahayu R, Sugita S. Efektivitas Pemberian Aromaterapi Lavender Dan Jahe Terhadap Penurunan Frekuensi Mual Muntah Pada Ibu Hamil Trimester I Di BPM Trucuk Klaten. J Kebidanan dan Kesehat Tradis. 2018;3(1):19-26.

18. Peterfalvi A, Miko E, Nagy T, Reger B, Simon D, Miseta A, et al. Much more than a pleasant scent: $A$ review on essential oils supporting the immune system. Molecules. 2019;24(24):1-16.

19. Sari RI. Pengaruh Aromaterapi Peppermint Terhadap Penurunan Mual Muntah Akut Pada Pasien yang Menjalani Kemoterapi di SMC RS Telogorejo. Pengaruh Aromaterapi Peppermint Terhadap Penurunan Mual Muntah Akut Pada Pasien yang Menjalani Kemoterapi di SMC RS Telogorejo [Internet]. 2015;4(2):1-9. 